\title{
INVESTIGATION OF TITANIUM-DIOXIDE COATINGS ON MEMBRANE FILTRATION PROPERTIES
}

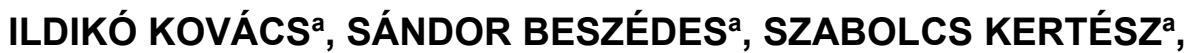 \\ GÁBOR VERÉB ${ }^{a}$, CECILIA HODÚR ${ }^{a}$, IBOLYA ZITA PAPP ${ }^{b}$, \\ ÁKOS KUKOVECZ ${ }^{\mathrm{b}, \mathrm{c}}$, ZSUZSANNA LÁSZLÓa*
}

\begin{abstract}
In this study, synthesized $\mathrm{TiO}_{2}$ nanorods and commercial Aeroxide $\mathrm{P} 25 \mathrm{TiO}_{2}$ nanoparticles were deposited on polyethersulfone (PES) membrane surfaces to compare their photocatalytic activity and effects on membrane surface and filtration properties. The catalysts were deposited on the membrane surface by physical deposition. The effect of the $\mathrm{TiO}_{2}$ amount on the stability of the catalyst layer and its effect on membrane resistance in presence and absence of UV irradiation were investigated. $1.2 \mathrm{mg} / \mathrm{cm}^{2}$ catalyst coverage proved to be a minimal appropriate coverage to prevent membrane damage during UV irradiation. The catalysts formed hydrophilic layers on the surface, and in case of both catalyst the surface free energy increased compared to the neat membrane. The photocatalytic activity and retention of the modified membranes were tested spectrophotometrically by using Acid Red1, azo dye.
\end{abstract}

Keywords: membrane filtration, $\mathrm{TiO}_{2}$ coated membranes, photocatalysis, azo dye, Acid Red 1

\section{INTRODUCTION}

Polyethersulfone (PES) is a widely-used material in asymmetric membrane manufacturing, because of its good performances [1]; it has high mechanical strength, thermal stability, environmental endurance, and

a Department of Process Engineering, Faculty of Engineering, University of Szeged, $\mathrm{H}-6725$ Szeged, Moszkvai krt. 9., Hungary

b Department of Applied and Environmental Chemistry, University of Szeged, H-6720 Szeged, Rerrich Béla tér 1., Hungary

c MTA-SZTE "Lendület" Porous Nanocomposites Research Group, H-6720 Szeged, Rerrich Béla tér 1., Hungary

*Corresponding author: zsizsu@mk.u-szeged.hu 
processing [2, 3]. However, it has low permeability and high fouling tendency due to its inadequate hydrophilic property [1-3]. This limits its application as a membrane material. To overcome these flaws, it is possible to modify PES membranes to improve their hydrophilicity [2], since back-flushing and chemical cleaning are not providing a permanent solution against membrane fouling and require serious optimization [4].

Some authors specifically investigated approaches to modify PES membrane with $\mathrm{TiO}_{2}$ to increase its hydrophilicity and to decrease its tendency to fouling. $\mathrm{TiO}_{2}$ is favoured over other semiconductors due to its good physical and chemical properties, availability, photocatalytic activity, desirable hydrophilic and potential antifouling properties [5-7].

PES composite membrane modified by self-assembly of $\mathrm{TiO}_{2}$ nanoparticles showed good separation qualities and higher water flux compared to the unmodified membrane, improved thermal stability, and increased hydrophilicity [2, 8]. Three different modified PES membranes were compared by Rahimpour and co-workers [1]: $\mathrm{TiO}_{2}$-entrapped membranes, UV-irradiated $\mathrm{TiO}_{2}$-entrapped membranes, and UV-irradiated $\mathrm{TiO}_{2}$-deposited membranes. It was found that by adding $\mathrm{TiO}_{2}$ to the casting solution changes the morphology of the membrane, by making a more hydrophilic and porous structure that has photocatalytic activity. However, the $\mathrm{TiO}_{2}$-deposited membranes had superior characteristics in terms of fouling mitigation.

The membrane fouling properties are determined by the interactions between foulants and the membrane surface. These interactions are weak secondary forces such as van der Waals, hydrogen and electrostatic forces. The strength of these forces depends on the characteristics of the membrane such as wettability or surface free energy. Generally, it can be stated that higher hydrophilicity and lower surface free energy leads to lower fouling property $[6,9,10]$.

In this work PES microfiltration membranes were coated with commercial Aeroxide $\mathrm{P} 25 \mathrm{TiO}_{2}$ and synthesised $\mathrm{TiO}_{2}$ nanorods. The aim of the work was to examine and compare the two layers made of catalysts of different geometry and different hydrophilicity. Contact angle measurements were carried out to determine the effect of the catalyst layer on the membrane surfaces wettability and surface free energy. Acid Red 1 (AR1, Azophloxine) dye was used as a model pollutant to determine the photocatalytic activity of the $\mathrm{TiO}_{2} \mathrm{P} 25$ and $\mathrm{TiO}_{2} \mathrm{NR}$ layers. AR1 is a reactive azo dye belonging to the largest class of dyes commonly employed in textile industry [11]. 


\section{RESULTS AND DISCUSSION}

\section{Characterization of the used photocatalyst}

For the membrane coating a commercial and a self-prepared titanium dioxide photocatalyst was applied. The synthesised $\mathrm{TiO}_{2}$ "nanorods" $\left(\mathrm{TiO}_{2} \mathrm{NR}\right.$, Figure 1) can be characterized with $\sim 50-70 \mathrm{~nm}$ length, $\sim 20-30 \mathrm{~nm}$ width and a $\sim 54 \mathrm{~m}^{2} \mathrm{~g}^{-1}$ specific surface area (determined by nitrogen adsorption at $77 \mathrm{~K}$, using BET method). Based on the XRD diffractogram of $\mathrm{TiO}_{2} \mathrm{NR}$ (Figure 2) it consists of $100 \%$ anatase phase. Commercial Aeroxide P25 titanium dioxide (produced by Evonik Industries) was also used for our experiments, which have spherical shape with a primer particle size of $\sim 25 \mathrm{~nm}$ [12]; however, it should be noted that in a suspension it forms aggregates nearly $1 \mu \mathrm{m}$ in diameter [13]. This titania is a mixture of anatase $(90 \%)$ and rutile $(10 \%)$ phase, and it has similar specific surface area $\left(49 \mathrm{~m}^{2} \mathrm{~g}^{-1}\right)$ like our self-prepared $\mathrm{TiO}_{2}$ NR.

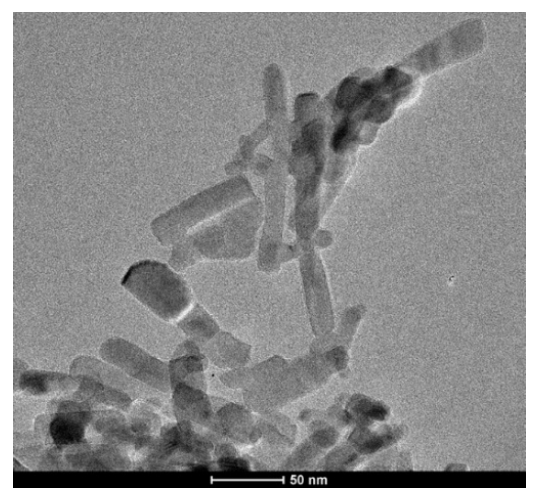

Figure 1. TEM image of titania nanorods $\left(\mathrm{TiO}_{2} \mathrm{NR}\right)$

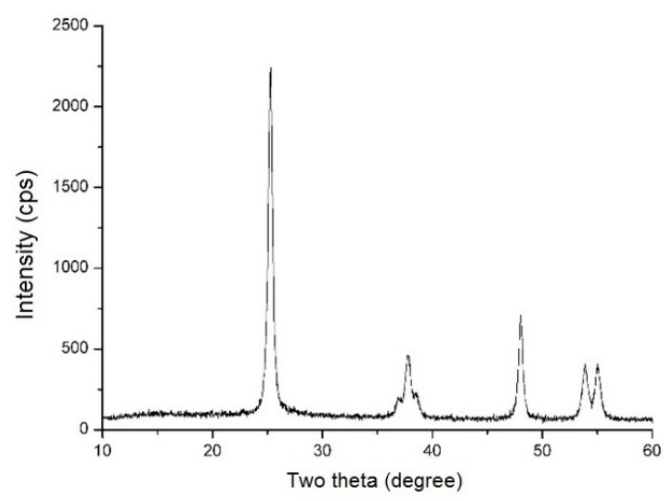

Figure 2. $\mathrm{XRD}$ of titania nanorods $\left(\mathrm{TiO}_{2} \mathrm{NR}\right)$ 


\section{Neat and $\mathrm{TiO}_{2}$ Coated Membrane Surface Property}

To investigate the effect of the catalyst layer on the membrane surface, $\mathrm{TiO}_{2}$ suspension was filtered through the membrane in a dead-end stirring cell to provide a specific cake layer. The SEM images of top surface of $0.6 \mathrm{~g} \mathrm{~cm}^{-2}$ $\mathrm{TiO}_{2} \mathrm{P} 25$ coated and the $0.6 \mathrm{~g} \mathrm{~cm}^{-2} \mathrm{TiO}_{2} \mathrm{NR}$ coated membranes are shown in Figure 3 . In case of both catalysts the aggregates are larger than the membrane pores, thus depositing on the surface, this amount of the catalysts does not provide a full coverage of the membrane and are not distributed uniformly. $\mathrm{TiO}_{2} \mathrm{P} 25$ forms a thick layer of uniform aggregates on the membrane surface. $\mathrm{TiO}_{2} \mathrm{NR}$ deposits on the surface forming different sized aggregates. To achieve better coverage of the membrane to protect from UV damage the amount of the catalyst was doubled, and its effect was investigated in further experiments.
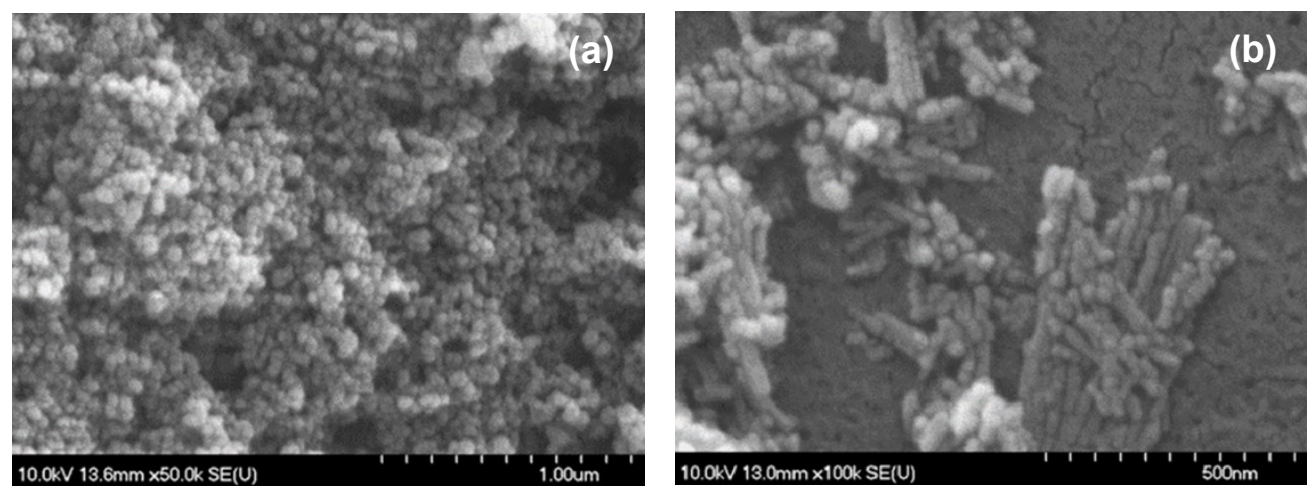

Figure 3. SEM images of top layers of (a) $0.6 \mathrm{~g} \mathrm{~cm}^{-2} \mathrm{TiO}_{2} \mathrm{P} 25$ coated, and (b) $0.6 \mathrm{~g} \mathrm{~cm}^{-2} \mathrm{TiO}_{2} \mathrm{NR}$ coated membranes

To characterize the wettability of the modified membrane surfaces, contact angles (with distilled water and glycerol) were measured and the surface free energy values were calculated. Figure 4 shows the contact angles of water and glycerol and the surface free energies. The contact angles of the $\mathrm{TiO}_{2}$ P25 coated membrane show that the catalyst forms a hydrophilic layer on the surface. The hydrophilicity of $\mathrm{TiO}_{2} \mathrm{NR}$ coated membranes also increased compared to the neat membranes. Reportedly, the reactivity of $\mathrm{TiO}_{2}$ surface and its affinity toward water is dependent on $\mathrm{TiO}_{2}$ crystal phase [14]. 

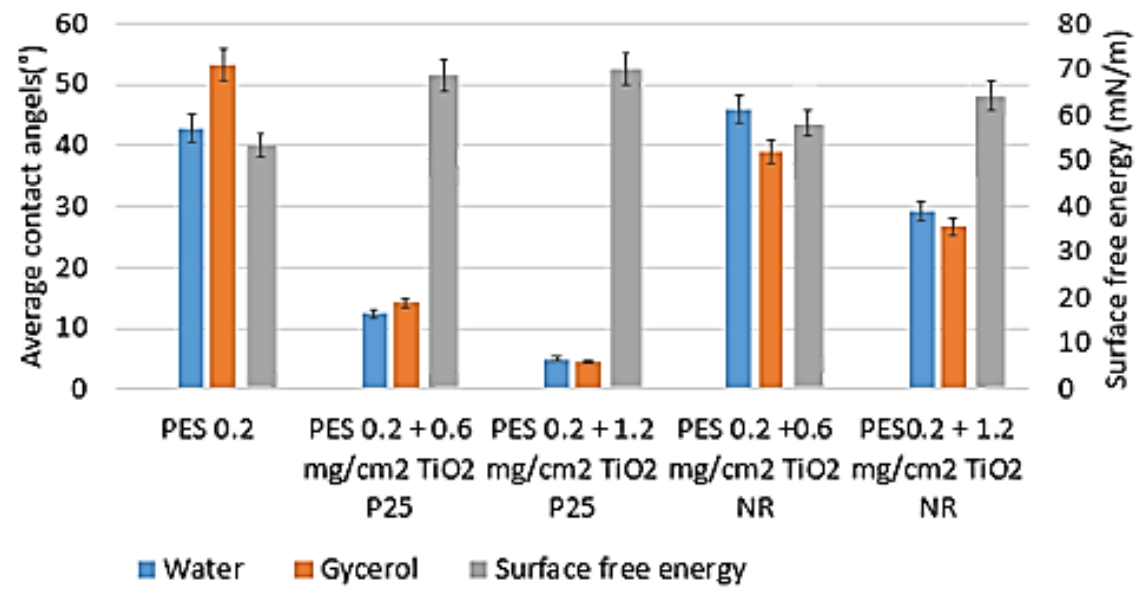

Figure 4. Contact angels of water and glycerol and surface free energies of neat and $\mathrm{TiO}_{2}$ coated membranes

\section{Investigation of the membrane stability under UV irradiation}

To investigate the effect of UV irradiation on the membrane stability, the membrane flux changes were measured and the membrane resistances were calculated before and after UV irradiation of the neat and coated membranes. It was found that the neat PES 0.2 membrane resistance (calculated by Equation (2)) decreased $30 \%$ after 1 hour UV $(\lambda=254 \mathrm{~nm})$ irradiation (Figure 5) due to its sensitivity to UV. According to the literature, similar decrease in membrane resistance was achieved after 24 hours of UV-A light irradiation of an ultrafiltration PES membrane $[15,16]$. This was attributed to the fact that PES contains sulphur that is highly susceptible to UV light. In the next series of experiments the effect of the amount of the catalyst on membrane stability under UV irradiation was examined. By coating the membrane with higher amounts of catalyst layer the decrease of membrane resistances were less extensive after 1 hour UV irradiation, since the catalyst layer absorbs the UV light. The $1.2 \mathrm{mg} / \mathrm{cm}^{2}$ catalyst layers in case of both types of $\mathrm{TiO}_{2}$ provided a sufficient coverage to be used for investigating the photocatalytic activity of the catalyst layer without extensive damage of the membrane during the irradiation.

To investigate the stability of the catalyst layer on the membrane surface, all coated membranes were left overnight in the stirring cell. $100 \mathrm{~mL}$ distilled water with $300 \mathrm{rpm}$ for 24 hours was stirred over them to check if the layer would wash off during operation. It was found that the turbidity of the distilled water did not change; the catalyst did not resuspend thus the $\mathrm{TiO}_{2}$ coating did not wash off. 


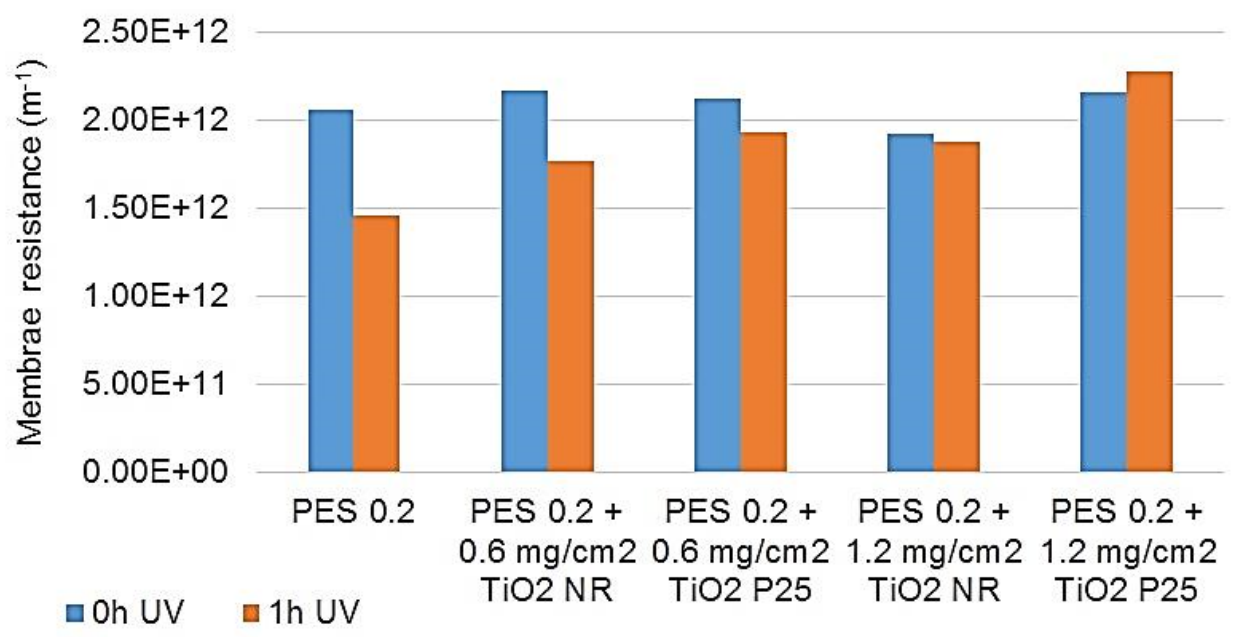

Figure 5. Changes of resistances of neat and $\mathrm{TiO}_{2}$ coated PES 0.2 membranes before and after UV irradiation

\section{Photocatalytic activity of the catalyst coated membranes}

The photocatalytic efficiencies of the catalyst layers were characterized by the decolourization of Acid Red 1 dye solution. In the first series of experiments the effect of UV irradiation on the decolourization of Acid Red1 was examined. During these experiments $100 \mathrm{~mL}$ of $15 \mathrm{mg} / \mathrm{L}$ Acid Red 1 solution was UV irradiated for an hour, and it was found that the irradiation alone did not result in colour intensity change of the solution. The photocatalytic activity of the coatings was examined in two different experimental arrangements. First, a 1 hour UV irradiation was used as a pre-treatment in the presence of the coated membrane, which was followed by the filtration. Secondly, the photocatalysis was performed during the filtration.

First, the retention of the neat membrane was measured and calculated by filtering the dye solution through it, using Equation (3). The $\mathrm{TiO}_{2}$ coated membranes had different retention values compared to the neat membrane (Figure 6). The $\mathrm{TiO}_{2} \mathrm{P} 25$ coating resulted in a $26 \%$ increase of the retention, which can be explained with the dense structure of the $\mathrm{TiO}_{2}$ layer [17], the layer behaves as an additional filtration layer which can adsorb the positively charged dye ions, due to its hydrophilic character. The $\mathrm{TiO}_{2} \mathrm{NR}$ coating resulted in a $62 \%$ retention decline compared to the neat membrane. The $\mathrm{TiO}_{2} \mathrm{NR}$ coating prevents the dye molecules from adsorbing on the membrane surface, due to its lower surface free energy compared to $\mathrm{TiO}_{2} \mathrm{P} 25$, which means that this surface is less prone to fouling. 

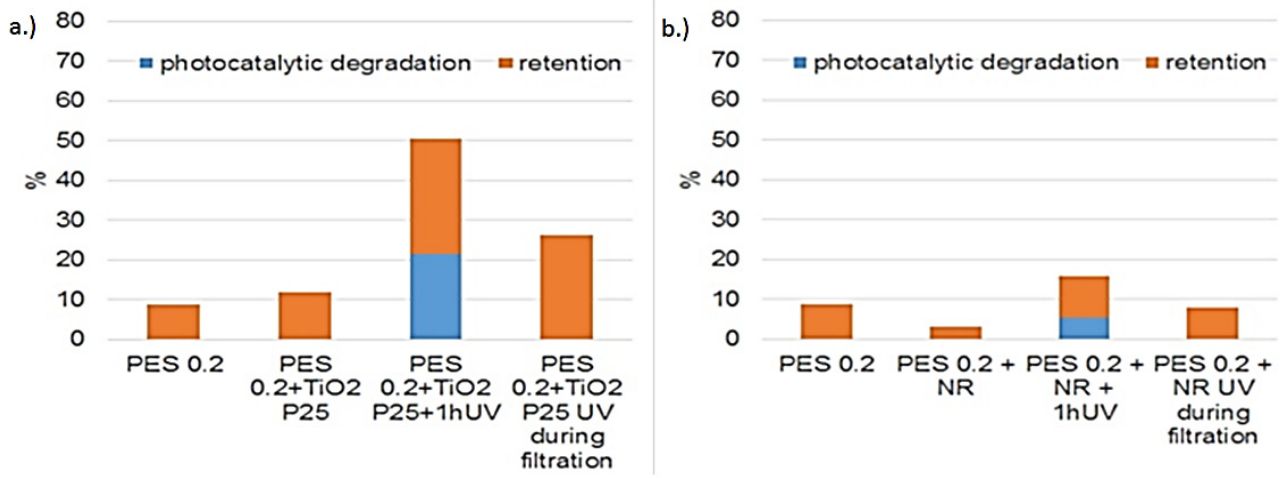

Figure 6. Neat and $\mathrm{TiO}_{2} \mathrm{P} 25$ (a.) and $\mathrm{TiO}_{2} \mathrm{NR}$ (b.) coated membrane dye retention

It was found that as a pre-treatment, irradiating the solution in the presence of the $\mathrm{TiO}_{2} \mathrm{P} 25$ coated membrane for an hour resulted in a $22 \%$ decolourization of the dye; this was only $8 \%$ in case of the $\mathrm{TiO}_{2} \mathrm{NR}$ coating. These results prove that the catalyst layers have photocatalytic activity, which means that the reactive species generated by heterogeneous photocatalysis react with the dye molecules. These results show that the efficiency of the photocatalytic degradation depends on the adsorption ability of the organic molecules on the catalyst surface: since the dye is less prone to adsorb on the surface of the $\mathrm{TiO}_{2} \mathrm{NR}$ coated membrane the efficiency of photocatalytic reaction is lower.

Filtering of the pre-treated solution through the $\mathrm{TiO}_{2} \mathrm{P} 25$ coated membrane resulted in a nearly $50 \%$ dye retention. In case of the $\mathrm{TiO}_{2} \mathrm{NP}$ coated membrane the membrane retention was significantly higher than the neat membrane retention, but significantly lower compared to the $\mathrm{TiO}_{2} \mathrm{P} 25$ coated membrane. In the case of continuous irradiation during filtration through the $\mathrm{TiO}_{2} \mathrm{P} 25$ and $\mathrm{TiO}_{2} \mathrm{NP}$ coated membranes the retention was lower compared to the pre-treatment that was followed by the filtration due to shorter exposure to the UV irradiation. In case of the pre-treatment the irradiation time was 1 hour while the simultaneous irradiation and filtration lasted for only 6 minutes.

\section{CONCLUSIONS}

Polyethersulfone microfiltration membranes were coated with commercial $\mathrm{TiO}_{2} \mathrm{P} 25$ and synthetized $\mathrm{TiO}_{2} \mathrm{NR}$. The minimal appropriate catalyst coverage of the membrane surface was determined to be $1.2 \mathrm{mg} / \mathrm{cm}^{2}$, to create a stabile coating which adsorbs the UV making the membrane withstand the irradiation. 
The coated membrane surfaces become more hydrophilic compared to the neat membrane, and the catalyst layer resulted in a higher surface free energy. The results showed that the surface hydrophilicity and the surface free energy determined the adsorption ability of the dye particles; the more hydrophilic $\mathrm{TiO}_{2} \mathrm{P} 25$ coating adsorbed higher amount of dye. Based on the results the surface free energy is in relation with the photocatalytic activity of the catalyst coating; the $\mathrm{TiO}_{2} \mathrm{NR}$ coated membranes have lower surface free energy, which means that it is less prone to adsorb dye particles, and this type of modified membrane showed lower photocatalytic activity, even though the specific surface area was similar in both cases.

\section{EXPERIMENTAL SECTION}

$\mathrm{TiO}_{2}$ (anatase) (BA01-01), $\mathrm{TiO}_{2} \mathrm{P} 25$ (AEROXIDE) and Acid red1 were supplied by UNIVAR, EVONIC Industries and Synthesia respectively. The concentration of AR1 solution used in membrane filtration measurements was $15 \mathrm{mg} / \mathrm{L}$.

The preparation of $\mathrm{TiO}_{2}$ nanorods were as follows: in $1 \mathrm{~L}$ of a $10 \mathrm{M}$ $\mathrm{NaOH}$ solution $250 \mathrm{~g} \mathrm{TiO}_{2}$ (anatase) was suspended, then for 24 hours the suspension was stirred in a rotating autoclave at $3 \mathrm{rpm}$ and $155^{\circ} \mathrm{C}$. Than the resulting product was washed and protonated with $0.1 \mathrm{M} \mathrm{HCl}$, after maintaining a $\mathrm{pH}$ value between 3 and 4 for 30 minutes the product was washed with $0.01 \mathrm{M}$ $\mathrm{HCl}$ for 3 days than with distilled water to remove the remaining chloride ions. The resulting $\mathrm{TiO}_{2}$ nanotubes were dried at $80^{\circ} \mathrm{C}$ for a day. The $\mathrm{TiO}_{2}$ nanotubes (NT) were than heat treated at $600^{\circ} \mathrm{C}$ for 6 hours. As a resulting product $\mathrm{TiO}_{2}$ nanorods $\left(\mathrm{TiO}_{2} \mathrm{NR}\right)$ arose.

Polyethersulfone membranes (PES-MF (NEW LOGIC Research INC, USA) with a $0.2 \mu \mathrm{m}$ were coated with commercial $\mathrm{TiO}_{2} \mathrm{P} 25$ and synthesized $\mathrm{TiO}_{2} \mathrm{NR}$. The membranes were coated by filtering through the membrane 50 $\mathrm{mL}$ and $100 \mathrm{~mL} 0.4 \mathrm{~g} / \mathrm{L}$ catalyst suspension in a dead end cell, at $0.1 \mathrm{MPa}$ without stirring, that resulted in 0.6 and $1.2 \mathrm{mg} / \mathrm{cm}^{2} \mathrm{TiO}_{2}$ coating respectively. The filtration was carried out with a Millipore batch filtration unit (XFUF04701, Solvent-resistant Stirred Ultrafiltration Cell, Millipore, USA). For the photocatalytic tests were carried out by the presence of the catalyst coating and UV irradiation, the stirring cell cap was modified and a UV light source was fitted in it (Fig. 7). This way a photocatalytic membrane reactor was set up. The UV light source was a low pressure mercury-vapour-lamp (GERMIPAK LightTech, Hungary, $40 \mathrm{~W}, \lambda=254 \mathrm{~nm}$ ). The filtrations of the dye solution were carried out at $0.1 \mathrm{MPa}$ transmembrane pressure, without stirring at $20^{\circ} \mathrm{C}$. In case of every filtration $100 \mathrm{~mL}$ water or dye solution was filtered to volume reduction ratio 5 $(\mathrm{VVR}=5)$. VRR [-], was defined as: 


$$
V R R=\frac{V_{F}}{V_{F}-V_{P}}
$$

where $V_{F}$ and $V_{P}$ is the volume of the feed and permeate $\left[\mathrm{m}^{3}\right]$ respectively at any time.

The membrane resistance $\left(R_{M}\right)$ was calculated as [18]:

$$
R_{M}=\frac{\Delta \mathrm{p}}{J_{w} \eta_{w}}\left[m^{-1}\right]
$$

where $\Delta p$ is the transmembrane pressure $(\mathrm{Pa}), \mathrm{J}_{\mathrm{w}}$ is the water flux of the clean membrane and $\eta_{w}$ is the viscosity of the water (Pas).

The retention values were calculated by the following equation:

$$
R=\left(1-\frac{c}{c_{0}}\right) 100 \%
$$

where $\mathrm{c}$ is the concentration of the permeate phase, and $\mathrm{c}_{0}$ is the concentration of the feed, both calculated form the absorbance of the solutions.

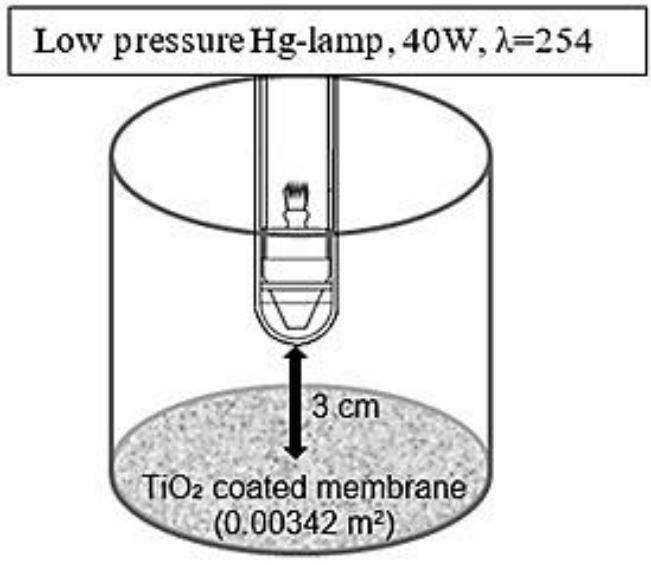

Figure 7. Schematic of the photocatalytic membrane reactor

UV irradiation of certain samples was done in the dead end cell before the filtration as a pre-treatment for 60 minutes and during the filtrations for as long as the filtration lasted.

Transmission electron microscopy (TEM; Philips CM10) images were recorded to determine the morphology and size of the $\mathrm{TiO}_{2} \mathrm{NT}$ and $\mathrm{TiO}_{2} \mathrm{NR}$. The nitrogen adsorption isotherms were recorded at $77 \mathrm{~K}$ using a QuantaChrome Nova 2000 surface area analyzer. Before the nitrogen adsorption, the samples were outgassed at $423 \mathrm{~K}$ for $1 \mathrm{~h}$ to remove any adsorbed contaminants. The specific surface areas were calculated from multipoint BET method. 
During $X R D$ measurements, titania nanorods were registered in the $2 \Theta=10-60^{\circ}$ range on a Rigaku Miniflex II instrument, using Cu Ka $(\lambda=$ $1.5418 \AA$ ) radiation.

The concentration of the dye was measured by spectrophotometer (Nanocolor® UV/Vis, Macherey-Nagel GmbH, Germany) at $\lambda=532 \mathrm{~nm}$.

Membrane hydrophobicity was quantified by measuring the contact angle that was formed between the (neat and coated) membrane surface and distilled water. $10 \mu \mathrm{L}$ water was carefully dropped on the top of the membrane surface and immediately measured, within 30 seconds. Contact angles were measured using the sessile drop method (Dataphysics Contact Angle System OCA15Pro, Germany). The measurements were repeated five times and the average value was calculated and is presented in this work. The surface free energies of membranes were calculated by the Owens, Wrndet, Rabel, and Kaelble (OWRK) method, using the OCA15 software package (Dataphysics).

\section{ACKNOWLEDGMENTS}

The János Bolyai Research Scholarship of the Hungarian Academy of Sciences supported this project. The authors are also grateful for the financial support provided by the project Hungarian Science and Research Foundation (NKFI contract number K112096).

\section{REFERENCES}

1. A. Rahimpour, S. S. Madaeni, A.H. Taheri, Y. Moghaddam, Journal of Membrane Science, 2008, 313, 158.

2. M.L. Luo, J.Q. Zhao, W. Tang, C.S. Pu, Applied Surface Science, 2005, 249, 76.

3. Y. Mansourpanah, S.S. Madaeni, A. Rahimpour, A. Farhadian, A.H. Taheri, Journal of Membrane Science, 2009, 330, 297.

4. A.H. Moghaddam, J. Shayegan, J. Sargolzaei, Journal of the Taiwan Institute of Chemical Engineers, 2016, 62, 150.

5. V. Vatanpour, S.S. Maadaeni, R.A. Khataee, E. Salehi, S. Zinadini, A.H. Monfared, Desalination, 2012, 292, 19.

6. A. Razmjou, J. Mansouri, V. Chen, Journal of Membrane Science, 2011, 378 (1-2), 73.

7. S. Leong, A. Razmjou, K. Wang, K. Hapgood, X. Zhang, H. Wang, Journal of Membrane Science, 2014, 472, 167.

8. J.F. Li, Z.L. Xu, H. Yang, L.Y. Yu, M. Liu, Applied Surface Science, 2009, 255, 4725. 
9. K.H. Choo, C. H. Lee, Journal of Colloidal and Interface Science, 2000, 226, 367.

10. G. Belfort, R.H. Davis, A. Zydney, Journal of Membrane Science, 1994, 96, 1.

11. Cs. Földváry, L. Wojnárovits, Radiation Physics and Chemistry, 2007, 76, 1485.

12. G. Veréb, Z. Ambrus, Zs. Pap, Á. Kmetykó, A. Dombi, V. Danciu, A. Cheesman, K. Mogyorósi, Applied Catalysis A: General, 2012, 417-418, 26.

13. K. Mogyorósi, N. Balázs, D.F. Srankó, E. Tombácz, I. Dékány, A. Oszkó, P. Sipos, A. Dombi, Applied Catalysis B: Environmental, 2010, 96, 577.

14. Z.X. Low, Z. Wang, S. Leong, A. Razmjou, L.F. Dumée, X. Zhang, H. Wang, Industrial \& Engineering Chemistry Research, 2015, 54, 11188.

15. S.S. Chin, K. Chiang, A.G. Fane, Journal of Membrane Science, 2016, 275, 202.

16. N.S. Allen, M. Edge, "Fundamentals of Polymer Degradation and Stabilization", Elsevier Applied Science, London, 1992, chapter 1.

17. H. Bai, Z. Liu, D.D. Sun, Chemical Communications, 2010, 46, 6542.

18. S. Kertész, Z. László, E. Forgács, G. Szabó, C. Hodúr, Desalination and Water Treatment, 2012, 35, 195. 
